\title{
A "INSEPARABILIDADE" DOS TRÂNSITOS NA OBRA DE DJAIMILIA PEREIRA DE ALMEIDA ${ }^{1}$
}

\section{THE "INSEPARABILIDADE" OF TRANSITS IN THE WORKS OF DJAIMILIA PEREIRA DE ALMEIDA}

Roberta Guimarães Franco ${ }^{2}$

\section{RESUMO}

A partir do conceito de "inseparabilidade", publicado por Djaimilia Pereira de Almeida em ensaio homônimo como parte do livro Pintado com o pé (2019), este artigo propõe uma leitura de quatro obras da escritora, a saber: Esse cabelo (2015), Luanda, Lisboa, Paraíso (2018), As telefones (2020) e Maremoto (2021). Em comum, os quatro livros apresentam histórias de imigração, majoritariamente entre Angola e Portugal, não aquela ligada ao movimento dos retornados, já amplamente trabalhado pela literatura portuguesa, mas a de uma geração posterior ao período da descolonização, portanto, vivenciada já a partir da década de oitenta. Como indica o texto da orelha de suas obras (com exceção das duas últimas publicações, mudança editorial relevante), Djaimilia "nasceu em Angola, cresceu em Portugal, vive nos subúrbios de Lisboa", portanto, sua inserção na literatura portuguesa contemporânea, a despeito do lugar marcado pelo mercado editorial, também merece atenção. Afinal, a reflexão sobre uma memória/história pública da colonização, para além dos testemunhos dos partícipes da guerra/da descolonização ou da segunda geração (pós-memória), que englobe a diáspora das populações das ex-colônias e ressignifique o espaço da antiga metrópole, ainda está por ser feita. Por fim, reflete-se sobre a necessidade de pensar a obra de Djaimilia Pereira de Almeida não apenas pela recorte pós-colonial, mas também passando pelo conceito de "post-migration" para compreender a sua escrita como uma memória outra na literatura portuguesa pós-25 de abril.

PALAVRAS-CHAVE: Inseparabilidade. Migração. Post-migration. 


\section{ABSTRACT}

Based on the concept of "inseparabilidade", published by Djaimilia Pereira de Almeida in an essay of the same name in Pintado com o pé (2019), this article offers a reading of four works by the writer: Esse cabelo (2015), Luanda, Lisboa, Paraíso (2018), As telefones (2020) e Maremoto (2021). As a shared characteristic, the four books tell stories of immigration, mostly between Angola and Portugal. However, these stories are not linked to the "retornados", which have already been thoroughly investigated by Portuguese literature, but to a generation starting in the 1980s following the period decolonization. As often indicated in the author bio included in her books (with the exception of the last two, a significant editorial change), Djaimilia "was born in Angola, grew up in Portugal, and lives in the periphery of Lisboa", and as such, her insertion in contemporary Portuguese literature, in spite of the space set by the publishing business, is also deserving of attention. After all, there is yet to be a reflection over a public memory/history of colonization, beyond the testimonies of those who were part of the war/decolonization process or their descendants (postmemory), that encompasses the diaspora of the populations of the former colonies and resignifies the space of the old metropole. Finally, we consider the need to think about Djaimilia Pereira de Almeida not only through the lens of postcoloniality, but also through the concept of "post-migration" in order to understand her writing as a diverging memory in post-Abril 25th Portuguese literature.

KEYWORDS: Inseparabilidade. Migration. Postmigration.

'O que é uma pessoa, tirando o que está disperso por tantos lugares?' A resposta talvez: 'Nada a que possamos chamar uma pessoa.'

Djaimilia Pereira de Almeida ${ }^{3}$

Toni Morrison, no livro A origem dos outros: seis ensaios sobre racismo e literatura (2019), resultado de um conjunto de conferências realizadas em Harvard sobre a "literatura do pertencimento", relata o episódio quando ainda criança conheceu a sua bisavó. A parteira, tida como uma espécie de lenda familiar, resolvera fazer uma série de visitas aos parentes, mas a espera pela matriarca converte-se em um caso de constrangimento quando, ao olhar para Morrison e sua irmã, a bisavó profere a sua constatação: "Essas crianças foram adulteradas” (2019, p. 22). A lembrança da infância, não-traumática em um primeiro momento, já que a percepção da criança não teria alcançado a dimensão racial da observação da bisavó, transformar-se em mote para uma série de obras da escritora:

Tenho uma dívida com a minha bisavó, uma dívida profunda. Embora ela não tenha tido nenhuma intenção de ajudar, pois não tinha remédio para a nossa deficiência, ela mesmo assim despertou em mim uma curiosidade que influenciou grande parte da minha obra. O olho mais azul é minha primeira ex- 
ploração do dano causado pela autodepreciação racial. Mais tarde examinei o conceito de seu oposto, a superioridade racial, em Paraíso. Em Deus ajude essa criança, mais uma vez me debrucei sobre o triunfalismo e o engodo promovidos pelo colorismo. Escrevi sobre suas falhas, sua arrogância e sua eventual autodestruição. (2019, p. 37-38)

As reflexões a partir da retomada do episódio familiar são direcionadas para a percepção sobre como a "outremização" é construída em diferentes âmbitos e sempre apoiada por justificativas que objetivam a dominação: "A raça tem sido um parâmetro de diferenciação constante, assim como a riqueza, a classe e o gênero, todos relacionados ao poder e à necessidade de controle" (MORRISON, 2019, p. 24). Aqui, no entanto, chama a atenção como a autora assume a influência da experiência no âmbito doméstico, uma mostra de que as crianças não estão a salvo dos julgamentos raciais no interior de suas casas, como fator que contribuiu para suas escolhas literárias, ultrapassando a vivência individual e transportando para suas narrativas algo maior, que atinge toda a sociedade em múltiplas estruturas.

Em 2019, Djaimilia Pereira de Almeida publicou o livro Pintado com o pé, reunião de contos, crônicas e ensaios escritos entre 2013 e 2019. No ensaio intitulado "Inseparabilidade", a autora declara que procura "[...] esclarecer o sentido da expressão comum 'a minha vida', baseando-me na hipótese de que tal nos ajuda a perceber a relação de uma pessoa com aquilo de que ela é inseparável." (2019, p. 125). Partindo da perspectiva de Michael Thompson em Life and action, Djaimilia amplia a discussão sobre o caráter não-acidental dos processos naturais, focando a sua abordagem no conceito em si e desdobrando-o para as experiências individuais e para as relações interpessoais.

Uma pessoa não pode ser materialmente separada de algumas das coisas que fazem de si a pessoa que é. Por exemplo, existe um conjunto de relações de que não podemos ser separados no sentido material. Uma pessoa pode separar-se de um braço, mas não pode ser forçada a separar-se da relação que tem com esse braço (e muitas vezes só se apercebe dessa relação quanto é separada do braço). Analogamente, nenhuma pessoa pode separar-se do seu corpo inteiro ou excluir-se da relação que tem consigo mesma. (ALMEIDA, 2019, p. 136)

Ao associar o conceito trabalhado por Djaimilia ao episódio narrado por Tony Morrison e a relação construída posteriormente com a sua escrita, pensa-se a "inseparabilidade" da condição de imigrante de Djaimilia Pereira de Almeida com as suas obras. Refletindo sobre o exemplo de Thompson acerca do dente-de-leão, Djaimilia afirma que "[...] diríamos que uma planta de dente-de-leão é inseparável do processo que a tornou a planta que é [...]" (2019, p. 147), logo parece inegável o peso das vivências de alguém que migrou ainda criança de Angola para Portugal, diante de um contexto que remete ao recente passado colonial que liga os dois países, frente ao conjunto de livros que destacam como personagens centrais figuras que passam por situações semelhantes ${ }^{4}$. 
O mercado editorial apresentou Djaimilia ao público, nas orelhas de suas primeiras obras, também pela marca desta migração - "nasceu em Angola, cresceu em Portugal, vive nos subúrbios de Lisboa” -, como a indicar para os leitores uma espécie de "confiabilidade" na escrita ficcional. No entanto, a partir da mudança para a editora Relógio D’água, em 2019, o resumo biográfico foi suprimido e substituído pela referência às obras anteriores e aos prêmios recebidos. Tal alteração não deixa de ser um indício da inserção da escritora na literatura portuguesa contemporânea que, diante de uma condição de pós-colonialidade, precisa rever as fronteiras estabelecidas entre nacionalidade e sistema literário. Como afirma Djaimilia em "Inseparabilidade":

A relação de alguém com o seu país não é estritamente uma relação entre dois bocados de matéria - um corpo e um território. Assim, aquilo que faz de uma pessoa a pessoa que é extravasa o seu corpo. Isto é, muitas das relações (com outras coisas e pessoas) que constituem uma pessoa enquanto indivíduo são distintas do seu corpo. (ALMEIDA, 2019, p. 136)

Portanto, a supressão da referência ao local de nascimento da autora não elimina a relação de "inseparabilidade" levantada neste artigo, tendo em vista todo o material extraliterário que circula sobre Djaimilia e, especialmente, o diálogo existente entre as suas obras, que revisitam a questão da migração, sobretudo em contextos familiares.

Birgit Neumann, ao explicar o conceito "ficções de memória", destaca que ele pode ser aplicado a narrativas que demonstram os funcionamentos das memórias, mas também a histórias sobre o passado, de indivíduos ou culturas, em busca de respostas. Por fim, Neumann afirma que, neste segundo caso, as "histórias podem também ser chamadas de "ficções da memória", porque, muito frequentemente, revelam ser uma (re)construção imaginativa do passado em resposta a necessidades actuais." (Neumann, 2016, p. 268). Neste sentido, o conjunto de publicações de Djaimilia Pereira de Almeida, que parte de histórias familiares e descortina episódios de uma história diaspórica atlântica contemporânea, acaba por revelar o quanto ainda há por fazer sobre uma história pública da colonização em Portugal, especialmente quando falamos de um processo tardio que se prolonga em pleno século XX. Por isso, a recorrência do trânsito, entre Angola e Portugal, e as perspectivas sobre a cidade de Lisboa a partir do olhar do imigrante, trazem outras memórias, distintas dos testemunhos sobre o fim do Império, sobre a vida dos portugueses nas colônias ou da memória de segunda geração.

A demanda do presente frente ao passado recente da colonização passa por compreender o quanto Portugal (e a Europa) não pode se afastar desse histórico e muito menos se valer de um "pós-25 de abril” e considerá-lo desfecho definitivo de um processo de séculos. Como afirma o diretor da Companhia Teatral Hotel Europa, André Amálio, a persistência de um pensamento colonial racista é um dos fracassos do 25 de abril, por isso, dentre tantos temas, a peça "Amores pós-coloniais" traz a questão das 
relações interraciais e do preconceito que sofrem em Portugal (FRANCO, 2020). Ao focar sobretudo no âmbito privado, nas histórias familiares, os mapas construídos pelas obras de Djaimilia inserem outros corpos, sem deixar de evidenciar a invisibilidade que os caracteriza, demonstrando como nos mínimos contextos é possível vislumbrar a projeção de uma sociedade neocolonial, dialogando com os pressupostos de Spivak (2010) quando relaciona a subalternidade a um vazio de representação.

Em 2015, Djaimilia publica Esse cabelo, livro que a projetará também no Brasil dois anos depois. A edição portuguesa tem como subtítulo "A tragicomédia de um cabelo crespo que cruza a história de Portugal e Angola", já a edição brasileira, de 2017, apresenta uma modificação, suprimindo a ideia de história e substituindo a referência específica aos países pela imagem de fronteiras: "A tragicomédia de um cabelo crespo que cruza fronteiras". Diferenças à parte, o livro anuncia-se desde o início como uma narrativa sobre o cabelo da sua narradora em primeira pessoa: "A verdade é que a história do meu cabelo crespo cruza a história de pelo menos dois países e, panoramicamente, a história indireta da relação entre vários continentes: uma geopolítica" (2017, p. 10).

Portanto, engana-se quem, ao ler o título Esse cabelo, acha que o livro aborda somente as transformações estéticas de um cabelo ao longo da vida da narradora Mila. As mudanças obviamente estão lá, mas o livro apresenta uma "memória capilar" que não pertence só a Mila, ao contrário, estende-se pela sua história familiar e amplia-se nas vivências de milhares de imigrantes que precisam "lidar" com o seu cabelo crespo em um território (e ambientes) que não está "preparado" para isso. ${ }^{6}$ Desse modo, o cabelo de Mila é uma questão geracional, fruto da mestiçagem e que atravessa a percepção que a própria família da narradora tem sobre o seu cabelo. Mas é também, e sobretudo, uma questão geográfica e diaspórica, já que a sobrevivência do cabelo depende de uma busca incessante por quem o entenda: "A casa assombrada que é todo o cabeleireiro para a rapariga que sou é muitas vezes o que me sobra de África e da história da dignidade dos meus antepassados. Sobra-me, porém, em lamento e escovadelas reparadoras [...]." (2017, p. 11)

Para o leitor que conhece bem a cidade de Lisboa, aquela que está para além da sua região central e dos pontos turísticos, a narrativa de Djaimilia apresenta uma verdadeira cartografia da imigração africana, a partir da busca da narradora pelos salões. Imagens bastante familiares para quem - como já disse Saramago "Se podes olhar, vê. Se podes ver, repara" - repara como os salões e lojas de produtos específicos vão surgindo, mesmo nas estações de metro, quando nos afastamos da região central da capital portuguesa. Tais espaços congregam uma série de complexas questões, que passam pela sobrevivência econômica e étnico-cultural, e pela não menos importante questão estética, atrelada à autoaceitação que, por sua vez, depende de saber cuidar-se e encontrar alguém confiável a quem entregar os cabelos: 
Tudo aquilo com que posso contar é com um catálogo de salões, com a sua história de transformações étnicas no Portugal que me calho - das retornadas cinquentonas às manicuras moldavas obrigadas, a contragosto, ao método brasileiro, passando pelos episódios do retraimento da minha exuberância natural numa menina que, nas palavras de todas estas mulheres, "é muito clássica”. A história da entrega da aprendizagem da feminilidade a um espaço público que partilho, talvez, com outras pessoas não é o conto de fadas da mestiçagem, mas é uma história de reparação. (2017, p. 11)

Portanto, interessa voltar à ideia de "geopolítica" anunciada no início do livro, não tanto pela relação entre Portugal e Angola, mas pela consequente migração que levará, pelas linhas da narrativa sobre o cabelo de Mila, a outro mapa literário de Lisboa: “[...] lugares para fazer tranças, necessidade que tinha o condão de me ir ampliando Lisboa” (2017, p. 28). Esse mapa conduz às mais diversas periferias, por onde Mila transita para encontrar um destino para o seu cabelo e acaba por desvendar-lhe uma imagem inusitada, de um déjá-vu: "Reparo, porém, com surpresa, tal ser a expressão exata da minha memória de Angola” (2017, p. 28)

A memória despertada pela periferia revela o mapa desigual da condição do imigrante, especialmente os de pele negra, para quem determinados espaços são interditos, ou seja, encontramos aqui outro indício da "inseparabilidade", aquele que determina um espaço geográfico/social a ser ocupado pelos imigrantes.

Quais seriam as consequências íntimas do nosso conceito amputado de Lisboa, de as nossas esperanças andarem a reboque da reconfiguração dos Restauradores e do Colégio Militar, desvios no trânsito e no plano da calçada, da tubagem exposta sob tábuas de madeira, tapumes através de cujas frestas surpreendíamos o almoço e a higiene dos homens das obras, nossos conterrâneos, da perspectiva da abertura de megastores de discos, como se ali acorrêssemos para comprar café e luvas, admirar gatos à janela, beber uma ginjinha, posar com o Pessoa, e não apenas para, sem qualquer outro propósito, desentorpecer o espírito - e a vida dos lisboetas nos estivesse vedada, como a nossa lhes estava, e fossem eles os invisíveis? (2017, p. 43-44)

A Lisboa amputada, os homens das obras seus conterrâneos... imagens captadas por aqueles que são invisíveis aos outros e podem, por breves instantes e na imaginação, inverter a condição de transparentes e viver a vida de flaneur que só cabe aos outros, aos "naturais" da terra (aos brancos). A marca da invisibilidade será uma constante também nas obras posteriores de Djaimilia, mais um indício da "inseparabilidade", já que, a despeito do número significativo de imigrantes de origem africana que vivem em Portugal ${ }^{7}$, não somente a invisibilidade dos corpos, mas também a do passado colonial ainda permanece gritante ${ }^{8}$. 
O cabelo, como mote para viagens espaço-temporais (revisitação dos percursos feitos pelos seus antepassados, viagem entre Angola e Portugal e pelos subúrbios de Lisboa), conduz Mila em busca do encontro consigo mesma e da aceitação do próprio cabelo. Mas, consequentemente, a história de migração da narradora e daqueles que a antecederam - "Cheguei a Portugal em oitenta e cinco, vinda de Angola. O meu pai precedera-me em um ano regressando para um novo emprego [...]" (2017, p. 54) - leva a "inseparabilidade" entre a história familiar que gerou o seu cabelo e a condição atual do seu corpo imigrante que, ao fazer parte de uma minoria, vive entre apagamentos e empréstimos:

Estar em minoria não consiste apenas em tomar de empréstimo a iconografia da nossa intimidade; consiste em apagar o que pode existir de singular não na vida que vivemos, mas na que não vivemos. A história desse empréstimo parece ter pouco de coletivo. Assemelha-se antes a uma inaptidão pessoal para nos lembramos melhor de quem não chegamos a ser. (2017, p. 83)

Não à toa, Mila compara a sua trajetória, e consequentemente a de seu cabelo, à emblemática fotografia de Elizabeth Eckford, relembrando as perseguições sofridas na escola além dos comentários racistas que ouvia e ainda ouve, e compreendendo-se como uma auto perseguidora, que desfigura a si própria e esconde na sua timidez uma semelhança com as mulheres brancas da foto. Por fim, Mila conclui: "No Portugal que me calhou, foi apenas nos salões, antevendo a frustração de penteados sempre ao lado, que me descanso, o que me mostra que foi sobretudo nos salões, nesse intervalo subestimado, que fui de facto portuguesa." (2017, p. 117).

Se o Portugal que calhou à Mila foi o dos salões das periferias lisboetas, no romance publicado em 2018, Luanda, Lisboa, Paraíso, o bairro fictício de nome ambíguo, "Paraíso", é o único espaço que parece receber verdadeiramente, obviamente com uma série de precariedades, Cartola e Aquiles, pai e filho vindos de Angola. A viagem para Portugal, inicialmente para a realização de uma cirurgia para correção de um problema congênito de Aquiles, transforma-se em permanência, diante de um claro desejo de Cartola de inserir-se no sonhado espaço lisboeta.

As primeiras páginas do romance situam a difícil vivência familiar em Luanda, diante dos problemas de saúde de Glória após o parto de Aquiles e da projeção para um futuro ainda distante, quando o menino poderia fazer a cirurgia em Lisboa ao completar 15 anos. Assim, a vida de Cartola parece aprisionada nos cuidados da esposa e do filho e, especialmente, na expectativa da viagem que, silenciosamente, desenha-se como definitiva. Cartola sonha com as ruas de Lisboa, lembra de decorar os seus nomes, mas a realidade da capital portuguesa atropela-o e o silêncio vai se transformando em algo natural, assim como censurar comportamentos que o pudessem identificar como imigrante:

Foi ao perceber que referir-se ao seu passado passaria por sinal de bebedeira que Cartola chorou pela primeira vez em Lisboa, mas não lhe caiu nenhuma lágrima. Para o bem e para o mal, Aquiles testemunhou a autocensura do pai, ainda que pare- 
cesse esquecido de onde tinha vindo. Cartola mortificava-se de ter o filho como espectador da morte do homem que fora e de que, passado afinal tão pouco tempo, apenas a família de Luanda, com que falava ao telefone, se lembrava. (2018, p. 87)

A mudez da autocensura desdobra-se a cada sonho desfeito, ampliando também a distância entre pai e filho. Mesmo com a mudança para o bairro Paraíso, são raros os momentos de esperança vivenciados por Cartola e Aquiles, enquanto sobram dificuldades, limitações e privações de toda natureza. Assim, diferente da ruptura familiar causada pela distância, a relação entre pai e filho conhece a ruína no difícil convívio da imigração, negada por Aquiles e silenciada por Cartola:

O filho nem o ouvia nem desejava ser admitido no seu círculo. Tratava-o como se ele não soubesse o que dizia. Fizera-se à personagem que Cartola inventou para não o assustar com a sua origem. O rapaz via nele um companheiro de quarto arbitrário. Tomava por bravata o que tinha sido coragem e a tudo o resto por cobardia. A culpa era sua. Tinha condenado o filho a não ter história por medo de que ele não se conseguisse erguer se a conhecesse.

$[\ldots]$

No sétimo Outono, Aquiles deu-o como causa perdida. Sem o dizer, despachou-o como a um imigrante, condição que negava ser a sua. Sete anos de Lisboa Cartola babava-se a comer e, se tentava levantar a voz, engasgava-se. (2018, p. 152-153)

O bairro Paraíso parece jogar pai e filho para um nível de invisibilidade ainda maior, salvo a amizade construída com Pepe e, posteriormente, os cuidados com o menino Iuri. Cartola e Aquiles afastam-se da vida no centro capital, com exceção dos passeios que o filho faz à noite, quando se sente camuflado. A invisibilidade não passa apenas pela moradia na periferia ou pela cor da pele, é marcada pela condição de ilegalidade: "Aquiles e o pai estavam protegidos pela bruma que era a sua existência sem documento" (2018, p. 171). Dos sonhos construídos pelo pai, ainda durante a infância do filho acompanhada pela expectativa da cirurgia, de um Portugal-solução e acolhida, restou um desejo pela morte, que fosse além daquela experenciada em vida: "De Portugal, a cidadania dos mortos foi o seu único visto de residência” (2018, p. 223).

Já o lugar da mãe, presa pelas limitações da doença no seu quarto em Luanda e diante da permanência do filho e do marido em Lisboa, fica restrito às cartas e telefonemas - "Os telefonemas para Glória tornaram-se escassos por falta de dinheiro e porque lhe era insuportável interpretar ao telefone uma personagem de que apenas ela mantinha memória viva, obrigado que se sentia a mentir-lhe" (2018, p. 87) -, e a vivência é um eterno futuro adiado, sonhando com um reencontro, "Espera só até eu chegar aí e podermos montar a nossa casinha” (2018, p. 121), que parece não passar pela cabeça de Cartola: "De Lisboa, em cartas e telefonemas, Cartola ali- 
mentava as esperanças da mulher como quem rega o canteiro de flores de uma sepultura" (2018, p. 123-124). Os telefones e as cartas, grafadas em fonte distinta, entrecortam o texto do romance, demarcando a comunicação à distância. A abordagem sobre a comunicação diante da separação familiar como consequência da migração será retomada em um novo diálogo entre as obras de Djaimilia Pereira de Almeida. As telefones, publicado em 2020, retoma o tema do trânsito entre Angola e Portugal, e novamente de uma forma totalmente distinta das anteriores: Filomena e Solange, mãe e filha, sustentam a relação basicamente por telefone, motivo pelo qual o título da obra associa o artigo no plural feminino "as" ao substantivo masculino "telefone". A convivência limitada aos fios telefônicos levará a uma constante sensação de desconhecimento, declarada pela filha, não conhecer do corpo da mãe significa o próprio estranhamento: "Não conheço o teu corpo, Filomena. Não conheço o meu corpo. De olhos fechados, não me lembro da tua cara. De olhos fechados, não sei como é a minha cara. Conhecemo-nos por telefone" (2020, p. 9).

O tipo de relação entre mãe e filha já havia aparecido em Esse cabelo - mesmo que as personagens sejam outras -, a filha em Lisboa, a mãe em Luanda e o contato basicamente por telefone e esporadicamente na reencenação do trânsito entre Portugal e Angola: "Pouco vivemos juntos. Víamo-nos quando vinha a Portugal, ou então ia eu a Luanda para uns quinze dias vividos entre a alegria e a timidez" (2017, p. 74), ou ainda em "Era disso que ela me falava ao telefone nos anos decapitados em que pouco nos vimos [...]" (2017, p. 97). ${ }^{9}$ Em As telefones, no entanto, a relação é o eixo central da narrativa e impactará diretamente na estrutura da obra, formada por raros diálogos em discurso direto e por recorrentes silêncios que simulam a conversa ao telefone: "Se fosse uma peça de teatro, haveria um telefone no palco e elas em cena, faladoras, mas surdas. Falariam uma com a outra, sem se ouvirem nem se responderem. Duas tagarelas surdas." (2020, p. 27).

O livro é a marca da separação motivada pelo desejo de sobrevivência, tão comum a diversas histórias de migração que geram o esfacelamento familiar, a mãe que sacrifica o convívio com a filha, em prol de melhores condições de vida para a menina. Por isso, já no contexto de guerra civil angolana e diante da fome, Filomena envia Solange para viver com sua irmã, estabelecida em Lisboa. O desconhecimento dos corpos uma da outra é fruto desse afastamento precoce, mãe e filha alimentam-se, sonham e sobrevivem pelo telefone: "A distância entre nós, a morte. Para sobrevivermos, quando não estamos em linha, não existimos. O telefonema: uma ressureição semanal, seguida de nova escuridão. Habituámo-nos ao que as chamadas fizeram de nós. Emprenhámos pelos ouvidos" (2020, p. 11). Pelos ouvidos, ambas sonham com a vida da outra, imaginam como vivem e enganam-se, especialmente a mãe que viu na ida da filha para Portugal um futuro diferente do seu:

Os seus telefonemas não eram palavras, mas um sonho em andamento, cujo avesso era tudo o que não contavam uma à outra: a filha sonhando com a vivenda onde a mãe vivia, que nunca visitara, a mãe sonhando com o apartamento onde a sua menina haveria de ser a dona da casa. 
Viam-se quando calhava, após anos. Nunca tinham dinheiro para nada. Solange recebia a mãe, pobremente. Lá se compravam dois frangos, três beringelas. Batia-se um funje, choravam e riam. Nem a casa onde a filha vivia era como a mãe a sonhara, nem a sua era o lugar bonito que sonhara vir a ter quando era menina. Talvez os seus sonhos fossem só demasiado inocentes. (2020, p. 72-73)

Em As telefones, devido ao protagonismo do meio de comunicação e consequentemente a divisão mais constante da narrativa entre Luanda e Lisboa, a capital portuguesa não se constitui como o cenário privilegiado da história de migração de Solange. Lisboa e Luanda são os lugares dos raros encontros entre mãe e filha, o que faz da capital portuguesa um espaço de encantamento aos olhos da mãe, que pode ser apresentada à cidade pelas mãos da filha. Passear pelas ruas, olhar as montras, era quase um momento de inversão, em que a filha se tornava a mãe, a conduzir a ingenuidade do deslumbramento que, momentaneamente, a faz esquecer da guerra em Angola e das reais condições de vida da filha em Portugal.

Lisboa volta à cena central no recém-publicado Maremoto (abril, 2021). Se a imagem do esfacelamento familiar permanece, consequência da migração do Senhor Boa Morte, natural de Angola, da Guiné para Portugal, a cidade de Lisboa não é mais retratada a partir da sua periferia como acontece, majoritariamente, em Esse cabelo e também em Luanda, Lisboa, Paraíso. Maremoto traz a invisibilidade do imigrante no coração da capital portuguesa, mas especificamente entre a Rua António Maria Cardoso, onde Boa Morte guarda carros, e a paragem do 28 na Rua Loreto, onde vive Fatinha.

De todos os livros, em Maremato está a maior ruína familiar, causada pela guerra de independência da Guiné e consequente processo de migração de Boa Morte para Portugal, após ter lutado ao lado dos portugueses no conflito. A relação entre pai e filha só existe na escrita dos papeis em que Boa Morte trata a filha, Aurora - desconhecida, imaginada -, como remetente das memórias que alguém pode vir a encontrar após a sua morte. Mas, a exemplo da amizade entre Cartola e Pepe e da presença do menino Iuri em Luanda, Lisboa, Paraíso, em Maremoto vemos a formação de uma outra família, primeiro entre Boa Morte e Fatinha, depois em torno da construção e manutenção de uma horta comunitária nos fundos da pensão.

Boa Morte tem plena consciência da sua condição - " [...] sou um homem sem bagagem, filha, um marinheiro sem navio [...]. Minha terra são esses malucos do Chiado, ninguém nos vê pela rua, podemos andar esfarrapados, ninguém nos olha, mas nós vemo-nos uns aos outros, vivemos aí, na transparência [...]" (2021, p. 15) - por isso apega-se a escrita dos papeis, mesmo sem saber se algum dia Aurora irá conhecer a narrativa de vida do pai: "[...] nem sei qual é a tua morada para te enviar esse meu testemunho" (2021, p. 17). De modo semelhante, Boa Morte agarra-se à Fatinha, que vive em mundo paralelo, sem noção do tempo (permanece eternamente com 20 anos) e da sua própria história. Boa Morte dedica à amiga, que o chama de 
príncipe, uma atenção paternal que sabe que jamais poderá exercer junto à Aurora. Entre a escrita, os cuidados com Fatinha e com a horta, Boa Morte convive com uma hérnia umbilical, motivo de vergonha, que ele espera, entre os diversos sangramentos, que o leve ao fim que a guerra não levou.

No entanto, a trajetória de Boa Morte não é feita somente dessa consciência. O Ex-soldado sustenta, apesar dos pesadelos com a guerra e de certa culpa por ter matado "os seus", um orgulho por fazer parte da cidade, mesmo que de uma forma que não corresponda ao seu passado de luta: "Sei bem que estacionamento não é trabalho digno, mas, para mim, eu sou funcionário da cidade de Lisboa que ajuda os cidadãos nas suas diligências." (2021, p. 34). É justamente o orgulho que sente de Portugal, desde a guerra na Guiné, que o afasta da família, já que a sua mulher é a primeira a alertá-lo sobre o seu autoengano, ao afirmar que ele nunca será português. A reação de Boa Morte é agredir a mulher, responsável por escancarar a realidade que o seu desejo de pertencer a essa terra outra encobre. Anos depois, ao alimentar os papeis com os rastros dessa trajetória - de Angola à Guiné, da Guiné a Portugal - e tentar explicá-la para a filha, sua destinatária sem paradeiro, Boa Morte demonstra a sua ambígua percepção sobre o espaço que ocupa:

Portugal, como te explicar a ti que essa é minha terra, filha, sem ferir teu coração? Terra dum homem é a terra que ele cava, terra pela qual um homem mata, e eu matei por Portugal antes de conhecer as ruas de Lisboa.

$[\ldots]$

Minha terra me guardou lugar de farrapo, mas aceitei meu posto como filho de Deus aceita seu quinhão da colheita. Filho não escolhe seu pai, eu não escolhi meu país. Matei como um louco. A cada cadáver me entreguei a Portugal. Cheguei a Lisboa, em 1979, soldado de regresso à casa do seu pai, casa de meu pai são essas ruas por onde hoje caminho. Meu velho pai pobre não tinha mesa posta no dia do meu regresso nem foi avisado de que eu cheguei. Mas, mesmo assim, me estendeu porção da sua terra - Rua António Maria Cardoso - para eu lavrar com as minhas mãos e colher a minha colheita. (2021, p. 67)

Maremoto apresenta uma narrativa majoritariamente em primeira pessoa, que corresponde sobretudo ao ato da escrita dos papeis, uma escrita ora em busca de redenção, ou mesmo de punição - "Mas quem tinha de me matar eras tu, Aurora, por isso te escrevo, para que voltes e me faças pagar. Escrevo para te pedir que acabes comigo, que queimes estes papéis e amaldiçoes o meu nome, já que eu, por mais que queira, todo o dia tenho de aguentar o meu peso nas pernas [...]" (2021, p. 48) - ora como forma de materialidade e de inserção diante da invisibilidade constante. Boa Morte sonha, passa a fazer pequenas viagens de comboio por Lisboa, momentos em que se mistura e se confunde com a própria malha ferroviária que atravessa a cidade, não sem temer ser descoberto por não ter comprado o bilhete. “Que outra pátria será a minha, se não essa minha ilusão?” (2021, 
p. 72) é o questionamento de Boa Morte, ao esperar que a hérnia se rompa, ou que tenha coragem de se entregar ao Tejo, mas que, por fim, permanece transparente em meio à multidão na entrada do metro.

Voltando ao ensaio de Djaimilia, é relevante apontar que o conceito de "inseparabilidade" não está sendo pensado aqui apenas na relação entre a biografia da autora e sua escrita, mas também sobre o lugar desta escrita, e dos temas que aborda, na literatura portuguesa contemporânea. Ou seja, a inseparabilidade entre a existência desses corpos que habitam as narrativas de Djaimilia em um país com o passado colonial como é o de Portugal, pois como afirma Djaimilia: “[...] se poderia defender que a unidade entre determinados resultados e as circunstâncias que a eles deram origem é não-acidental, na medida em que esses resultados são inseparáveis dessas circunstâncias" (2019, p. 151)

Portanto, a inserção da obra de Djaimilia Pereira de Almeida na literatura portuguesa contemporânea é significativa para problematizar as memórias construídas em Portugal acerca do seu passado colonial recente e longínquo. Não é novidade, dentro dos estudos pós-coloniais, a necessidade de perceber os impactos do colonialismo como uma via de mão dupla, não existe apenas um movimento do colonizador em direção ao colonizado, não existe colonização sem que a cultura dominante seja atravessada pelas culturas que tenta dominar (HALL, 2003). Por isso, o deslocamento, quando falamos da migração das ex-colônias em direção às antigas metrópoles, é relevante para pensarmos as produções pós-coloniais: “A major feature of post-colonial literatures is the concern with place and displacement. It is here that the especial post-colonial crisis of identity comes into being; the concern with the development or recovery of an effective identifying relationship between self and place." (ASHCROFT; GRIFFITHS; TIFFIN, 2010, p. 8). Como afirma Margarida Calafate Ribeiro, a respeito de Luanda, Lisboa, Paraíso:

A viagem realizada por estes sujeitos constitui um reconhecimento de que grande parte da história que os/nos constitui se passou fora de Portugal e da Europa e que, para perceber a "fratura colonial" que os/nos marca a todos, tem que ser contada a história das pertenças e vinculações de muitos sujeitos àquelas outras terras outrora parte do império e desses outros sujeitos à história de Portugal. (RIBEIRO, 2019, p. 294)

Diante desses trânsitos, a questão da experiência ressurge como um elemento crucial para os textos pós-coloniais, tendo em vista que o testemunho de alteridade frente a séculos de narrativas que silenciaram tais vivências configura-se como movimento de saída do âmbito privado/ individual e atinge o público/coletivo, proporcionando uma memória outra: "In writing out of the condition of 'Otherness' post-colonial texts assert the complex of intersecting 'peripheries' as the actual substance of experience." (ASHCROFT; GRIFFITHS; TIFFIN, 2010, p. 77). Nesse sentido, no caso de Djaimilia Pereira de Almeida, é necessário refletir para além do pós-colonial, 
e sobretudo com outro conceito, o de post-migration, já que as noções de periferia e de alteridade são permeadas não só pela questão colonial, mas principalmente pela migração que se desenvolve em um contexto posterior. Assim: "The notion of a postmigrant society highlights the often forgotten and oppressed history of migration and challenges the tradicional logic of integration, based on the assumption of a stable and sedentary 'we-group', into which the 'Other' is expected to integrate." (PETERSEN; SCHRAMM; WIEGAND, 2019, p. 5)

Portanto, o conceito passa pela necessidade de inserção, mas não pela ideia de existência de um grupo homogêneo e estável ao qual o imigrante deve se integrar. Essa imagem de homogeneidade é notável no caso português, realimentada pelos mitos desenvolvidos durante o salazarismo, de um discurso sobre uma nação branca, cristã, católica. É justamente essa construção que estaria ameaçada pela migração: “[...] the discourse on postmigration tends to focus on migration-related internal affairs and struggles within white majority nations in which large parts of the population still cling to a crumbling image of the nation as homogeneously white" (PETERSEN, 2019, p. 76). Nesse sentido, quando falamos de Portugal, é inegável que a dificuldade de inserção é atravessada pela questão racial, para além dos fantasmas do fim do império.

No que se convencionou chamar de "literatura pós-25 de abril", vemos um boom de testemunhos, sobre a vida no ultramar, sobre a experiência da guerra, sobre o movimento dos retornados etc. Tais narrativas permitiram não apenas questionar os discursos produzidos e alimentados pelo Estado Novo, como rever a construção de um imaginário sobre a ideia de Império. Passamos dos testemunhos de um primeiro momento, das décadas de 70-80, para a pós-memória da segunda geração, que ganhou fôlego no século XXI, e vem proporcionando novas visões comparativas entre a metrópole e o ultramar. A partir do diálogo, por exemplo, entre os livros Caderno de memórias coloniais (2009), de Isabela Figueiredo, e O retorno (2012), de Dulce Maria Cardoso, vemos a relevância da contraposição entre a vida nas colônias e a chegada na metrópole:

As perspectivas dos dois livros são bastante distintas, mas nas duas obras, a distância temporal, que separa o tempo dos acontecimentos, das vivências, e o tempo da escrita, é crucial para pensarmos a pós-memória e o "investimento imaginativo" que não exclui o diálogo entre o ficcional e as experiências vividas pelas autoras nos espaços coloniais, mas também no retorno à metrópole. E este trânsito entre os dois lados - o lá e o aqui - se mostra significativo para a reconfiguração de uma ideia de Portugalidade, já que o contraste entre as imagens, as comparações entre a vida de lá e a vida daqui, bem como a comparação entre os discursos que eram reproduzidos em África sobre a metrópole e a visão deste espaço após o retorno, apresenta uma significativa desconstrução de um ideário sobre o Império. (FRANCO, 2018, p. 162) 
No entanto, se a literatura sobre/dos retornados, por exemplo, abriu caminho para repensar as relações entre "o lá e o aqui", ainda há uma barreira significativa quando o lá (África) invade o aqui (Portugal), quando a questão não é apenas o retorno, mas a imigração, quando os corpos são corpos negros. Por isso, o conceito de post-migration parece relevante para refletir sobre uma nova "portugalidade", constituída por essa memória residual em específico, que confronta também um imaginário de uma colonização portuguesa amena, alimentada pelas ideias lusotropicalistas, como questiona João Gorjão Henriques sobre até quando será sustentada a imagem de um colonizador "que não discriminava porque se miscigenou com as populações locais, quando sabemos que as obrigava a despirem-se da sua identidade africana [...] ? Até quando iremos contribuir para uma mentalidade acrítica sobre um dos fenómenos mais violentos da nossa história?” (2016, p. 15)

Das lutas pelas independências à luta por direitos básicos, os trânsitos migratórios mostram uma nova face da herança que os processos coloniais deixaram "lá e aqui" (nas ex-colônias e em Portugal). O conceito de "inseparabilidade" passa também pelas demandas do presente como consequência de um passado prolongado, das primeiras diásporas às histórias que se repetem a cada dia e não só pelas águas do Atlântico. Para Djaimilia, a inseparabilidade de uma pessoa da sua vida "fornece-nos um critério de justiça acerca do modo como entendemos e tratamos uma pessoa. Isto ajuda a explicar a injunção de que [...] a vida de cada pessoa dever ser tida em conta. Esta injunção é importante num mundo em que todos passamos o tempo a fazer o contrário." (2019, p. 193).

O critério de justiça apontado por Djaimilia passa pela inclusão dos trânsitos contemporâneos em Portugal como fruto de uma articulação histórica recorrentemente negada. A representação desses corpos invisibilizados de variadas formas traz consigo outras memórias que não só compõem o cenário do território português silenciado, mas confronta uma imagem alimentada de Império que, no entanto, se queria longe, no "lá" do ultramar. Assim, os corpos que habitam as obras de Djaimilia Pereira de Almeida ajudam a compor outras "ficções de memórias", de uma história pública ainda por fazer, de um talvez Império que não abandona seus monumentos celebratórios, mas nega a herança multicultural quando ela bate à porta.

\section{REFERÊNCIAS}

ALMEIDA, Djaimilia Pereira de. Esse cabelo: a tragicomédia de um cabelo crespo que cruza fronteiras. Rio de Janeiro: Leya, 2017.

ALMEIDA, Djaimilia Pereira de. Luanda, Lisboa, Paraíso. Lisboa: Companhia das Letras, 2018.

ALMEIDA, Djaimilia Pereira de. "Inseparabilidade". In: Pintado com o pé. Lisboa: Relógio D’água Editores, 2019, p. 125-193.

ALMEIDA, Djaimilia Pereira de. As telefones. Lisboa: Relógio D’água Editores, 2020. 
ALMEIDA, Djaimilia Pereira de. Maremoto. Lisboa: Relógio D’água Editores, 2021.

ASHCROFT, Bill; GRIFFITHS, Gareth; TIFFIN, Helen. The Empire writes back. New York: Routledge, 2010.

FRANCO, Roberta Guimarães. Portugalidade e pós-memória: configuração e desconstrução da identidade portuguesa no século XXI. In: CAMPOS, Laura Barbosa; CARRIZO, Silvia; MAGALHÃES, Pedro Armando (orgs). (Pós)-memória e transmissão na literatura contemporânea. Rio de Janeiro: ABRALIC, 2018, p. 153-166.

FRANCO, Roberta Guimarães. Memórias em trânsito: deslocamentos distópicos em três romances pós-coloniais. São Paulo: Alameda, 2019.

FRANCO, Roberta Guimarães (2020). Testemunhos em fragmentos: memórias do colonialismo português na peça Amores Pós-Coloniais. Gragoatá, 25(53), 993-1015. https://doi.org/10.22409/gragoata.v25i53.42957

HALL, Stuart. Da diáspora: identidades e mediações culturais. Tradução: Adelaine La Guardia Resende. Belo Horizonte: Editora UFMG, 2003.

HENRIQUES, Joana Gorjão. Racismo em português: o lado esquecido do colonialismo. Lisboa: Tinta da China, 2016.

MORRISON, Toni. A origem dos outros: seis ensaios sobre racismo e literatura. Tradução: Fernanda Abreu. São Paulo: Companhia das Letras, 2019.

NEUMANN, Birgit. A representação literária da memória. Tradução: Marta Pacheco Pinto In: ALVES, Fernanda Mota Alves; SOARES, Luísa Afonso; RODRIGUES, Cristiana Vasconcelos (orgs). Estudos da memória: teoria e análise cultural. Famalicão: Edições Húmus, 2016, p. 267-278.

ONDJAKI. O livro do deslembramento. Lisboa: Editorial Caminho, 2020.

PETERSEN, Anne Ring; SCHRAMM, Moritz; WIEGAND, Frauke. Introduction - From Artistic Intervention to Academic Discussion. In: SCHRAMM, Moritz; MOSLUND, Sten Pultz; PETERSEN, Anne Ring. Regraming migration, diversity and the arts: the postmigrant condition. New York: Routledge, 2019, p. 3-10.

PETERSEN, Anne Ring. 'Say It Loud!' A Postmigrant Perspective on Postcolonial Critique in Contemporary Art. In: SCHRAMM, Moritz; MOSLUND, Sten Pultz; PETERSEN, Anne Ring. Regraming migration, diversity and the arts: the postmigrant condition. New York: Routledge, 2019, p.75 - 93.

RIBEIRO, Margarida Calafate. Viagens na minha terra de "outros" ocidentais. In: RIBEIRO, Margarida Calafate; ROTHWELL, Phillip (orgs). Heranças pós-coloniais nas literaturas de língua portuguesa. Porto: Edições Afrontamento, 2019, p. 291-307. 
SPIVAK, Gayatri Chakravorty. Pode o subalterno falar? Tradução: Sandra Regina Goulart Almeida; Marcos Pereira Feitosa; André Pereira Feitosa. Belo Horizonte: Editora UFMG, 2010.

Recebido para avaliação em 31/05/2021
Aprovado para publicação em 13/06/2021

\section{NOTAS}

1 Este texto é um dos resultados do projeto "Poder e silêncio(s): a pós-colonialidade entre o discurso oficial e a criação ficcional”, financiado pela FAPEMIG.

2 Professora da Faculdade de Letras da Universidade Federal de Minas Gerais. Professora permanente do Programa de Pós-graduação em Letras da Universidade Federal de Lavras. Doutora em Estudos Literários (Literatura Comparada) pela Universidade Federal Fluminense, com período sanduíche no Centro de Estudos Sociais da Universidade Coimbra.

3 “Inseparabilidade” In: Pintado com o pé. Lisboa: Relógio d'água, 2019.

4 Não é o objetivo deste texto tratar da evidente questão autobiográfica no livro Esse cabelo (2015) e do seu desdobramento autoficional nos livros subsequentes, especialmente em As telefones (2020). No entanto, tais aspectos reforçam a questão da "inseparabilidade" abordada nesta proposta, tendo em vista a recorrência de temas e histórias familiares que se cruzam com a biografia de Djaimilia Pereira de Almeida.

5 Supõem-se que a mudança tenha sido realizada para atender aos interesses de um mercado editorial brasileiro focado no consumo ávido, nos últimos anos, por bibliografias referentes ao cabelo crespo e ao universo afro. Portanto, ampliar a imagem do livro, relacionando-o à ideia de fronteiras mas afastando-o da especificidade da relação entre Portugal e Angola, poderia ser um atrativo maior para o público brasileiro.

6 Quero deixar claro aqui que "lidar" significa muito mais do que pentear e tratar do próprio cabelo, mas "lidar" com a falta de aceitação social e a constante imposição de transformações para que ele seja aceito. $\mathrm{O}$ uso da palavra "preparado" também está aqui com dupla conotação, no sentido estético sobre a falta de produtos e técnicas adequadas para o tratamento do cabelo crespo, além da falta de preparo proposital daqueles que não desejam atender esse perfil de clientela.

7 Segundo o último relatório disponível do Serviço de Estrangeiros e Fronteiras (SEF) de Portugal e os dados sobre a população residente, em 2019 houve um aumento de 57,4\% no fluxo migratório vindo do continente africano, se comparado ao ano de 2018.

8 É importante ressaltar que esta discussão não é nova, apesar da insistência no seu silenciamento. Em 2007, por exemplo, a RTP organizou uma série documental intitulada "Portugal, um retrato social", um dos episódios, "Nós e os outros - uma sociedade plural", apresenta um Portugal que fala várias línguas e pratica diferentes religiões. Naquela época contanto oficialmente com - para citar apenas os oriundos dos países africanos de língua portuguesa - 60 mil cabo-verdianos, 30 mil angolanos e 20 mil guineenses. (FRANCO, 2019, p. 44-45)

9 No último romance de Ondjaki, O livro do deslembramento (2020), também há uma referência a este tipo de relação, ou seja, ao efeito que a migração tem na dispersão familiar por diversos territórios e como muitas das relações são mantidas quase que unicamente por telefone e como, em um contexto de guerra, o seu mau funcionamento leva ao desespero: "sem poder falar com os outros filhos que estavam em Portugal, e a preocupação dela não era por eles não estarem bem, porque até estavam melhor que nós, mas sim a preocupação de uma mãe que sabe do coração apertado dos filhos noutro país tão longe a não saberem notícias dos pais que anda ali num fim-de-semana cheio de guerra" (ONDJAKI, 2020, p. 223) 